\title{
THE
}

$1-27-2015$

\section{Validation of Recent Shear Wave Velocity Models in the United States with Full-Wave Simulation}

Haiying Gao

Yang Shen

University of Rhode Island, y.shen@icloud.com

Follow this and additional works at: https://digitalcommons.uri.edu/gsofacpubs

Terms of Use

All rights reserved under copyright.

\section{Citation/Publisher Attribution}

Haiying Gao and Yang Shen. (2015). "Validation of recent shear wave velocity models in the United States with full-wave simulation." Journal of Geophysical Research: Solid Earth, 120(1), 344-358.

Available at: https://doi.org/10.1002/2014JB011369

This Article is brought to you for free and open access by the Graduate School of Oceanography at DigitalCommons@URI. It has been accepted for inclusion in Graduate School of Oceanography Faculty Publications by an authorized administrator of DigitalCommons@URI. For more information, please contact digitalcommons-group@uri.edu. 


\section{QAGUPUBLICATIONS}

\section{Journal of Geophysical Research: Solid Earth}

\author{
RESEARCH ARTICLE \\ 10.1002/2014JB011369 \\ Key Points: \\ - Systematic validation of model accuracy \\ with full-wave propagation simulation \\ - Resolution of velocity models has \\ been improved over time \\ - A comprehensive Vp and Vs model \\ from the crust to the mantle is in need
}

Supporting Information:

- Text S1 and Figures S1-S5

Correspondence to:

H. Gao,

haiyinggao@geo.umass.edu

Citation:

Gao, H., and Y. Shen (2015), Validation of recent shear wave velocity models in the United States with full-wave simulation, J. Geophys. Res. Solid Earth, 120, 344-358, doi:10.1002/2014JB011369.

Received 9 JUN 2014

Accepted 9 DEC 2014

Accepted article online 13 DEC 2014

Published online 27 JAN 2015

\section{Validation of recent shear wave velocity models in the United States with full-wave simulation}

\author{
Haiying Gao ${ }^{1}$ and Yang Shen ${ }^{2}$ \\ ${ }^{1}$ Department of Geosciences, University of Massachusetts Amherst, Amherst, Massachusetts, USA, ${ }^{2}$ Graduate School of \\ Oceanography, University of Rhode Island, Narragansett, Rhode Island, USA
}

Abstract Interpretations of dynamic processes and the thermal and chemical structure of the Earth depend on the accuracy of Earth models. With the growing number of velocity models constructed with different tomographic methods and seismic data sets, there is an increasing need for a systematic way to validate model accuracy and resolution. This study selects five shear wave velocity models in the U.S. and simulates full-wave propagation within the 3-D structures. Surface-wave signals extracted from ambient seismic noise and regional earthquakes are compared with synthetic waveforms at multiple-frequency bands. Phase delays and cross-correlation coefficients between observed and synthetic waveforms allow us to compare and validate these models quantitatively. In general, measurements from regional earthquakes are consistent with ambient noise results, but appear more scattered, which may result from uncertainty of the earthquake source location, origin time, and moment tensor. Our results show the improvement of model prediction with the increase of seismic data sets and implement of advanced methods. There exists a positive linear trend between phase delay and interstation distance for three models, indicating that on average, these models are faster than the real Earth structure. The phase delays from the jointly inverted model of ambient noise and receiver function have negative means at all periods while without obvious dependence on the interstation distance. The full-wave ambient noise tomographic model predicts more accurate phase arrivals compared to other models. This study suggests a need for an integrated model constructed with multiple seismic waveforms and consideration of anisotropy and attenuation.

\section{Introduction}

Seismic tomography has been one of the main methods to study the structure of the Earth. An accurate velocity model is essential for the interpretation of underlying dynamic processes and our understanding of the temperature and composition of the Earth [Goes et al., 2000; Hammond and Humphreys, 2000; Takei, 2002; Cammarano et al., 2003; Godey et al., 2004; Faul and Jackson, 2005; Behn et al., 2009]. With the EarthScope USArray migrating from west to east of the United States, numerous $P$ and $S$ velocity models have been presented [e.g., Burdick et al., 2008, 2010; Bedle and van der Lee, 2009; Sigloch, 2011; Yuan et al., 2011; Simmons et al., 2012]. Particularly, the structures in the western and central U.S. have been constructed with great details [Roth et al., 2008; Yang et al., 2008; Abers et al., 2009; Audet et al., 2009; Moschetti et al., 2010; Obrebski et al., 2010, 2011; Schmandt and Humphreys, 2010; Calkins et al., 2011; Gao et al., 2011; Delorey and Vidale, 2011; James et al., 2011; Porritt et al., 2011, 2013; Wagner et al., 2012; Shen et al., 2013; Gao and Shen, 2014].

With the availability of these various models resolved from different methods and data sets comes the need to understand the accuracy and resolution of these models. Becker [2012] quantitatively documented the similarities and differences among several velocity perturbation models resolved from body wave tomography in the Pacific Northwest [Roth et al., 2008; Burdick et al., 2008, 2010; Obrebski et al., 2010, 2011; Schmandt and Humphreys, 2010, 2011; James et al., 2011; Sigloch, 2011]. Although the large-scale structures are found to be consistent among these models, the magnitudes of the velocity anomalies vary within a wide range, posing a challenge in using the velocity models to infer the thermal and compositional structures of the mantle in the region. Pavlis et al. [2012] discussed the geometry of the Farallon Plate inferred from the 3-D visualization of recent 3-D tomographic results [Bedle and van der Lee, 2009; Obrebski et al., 2010, 2011; Schmandt and Humphreys, 2010, 2011; Burdick et al., 2010; James et al., 2011; Pavlis et al., 2012; Sigloch, 2011; Tian et al., 2011].

Although the comparison of various models is informative, it does not provide an assessment on the validity of the models in predicting seismic observations. A more straightforward and powerful way to validate 

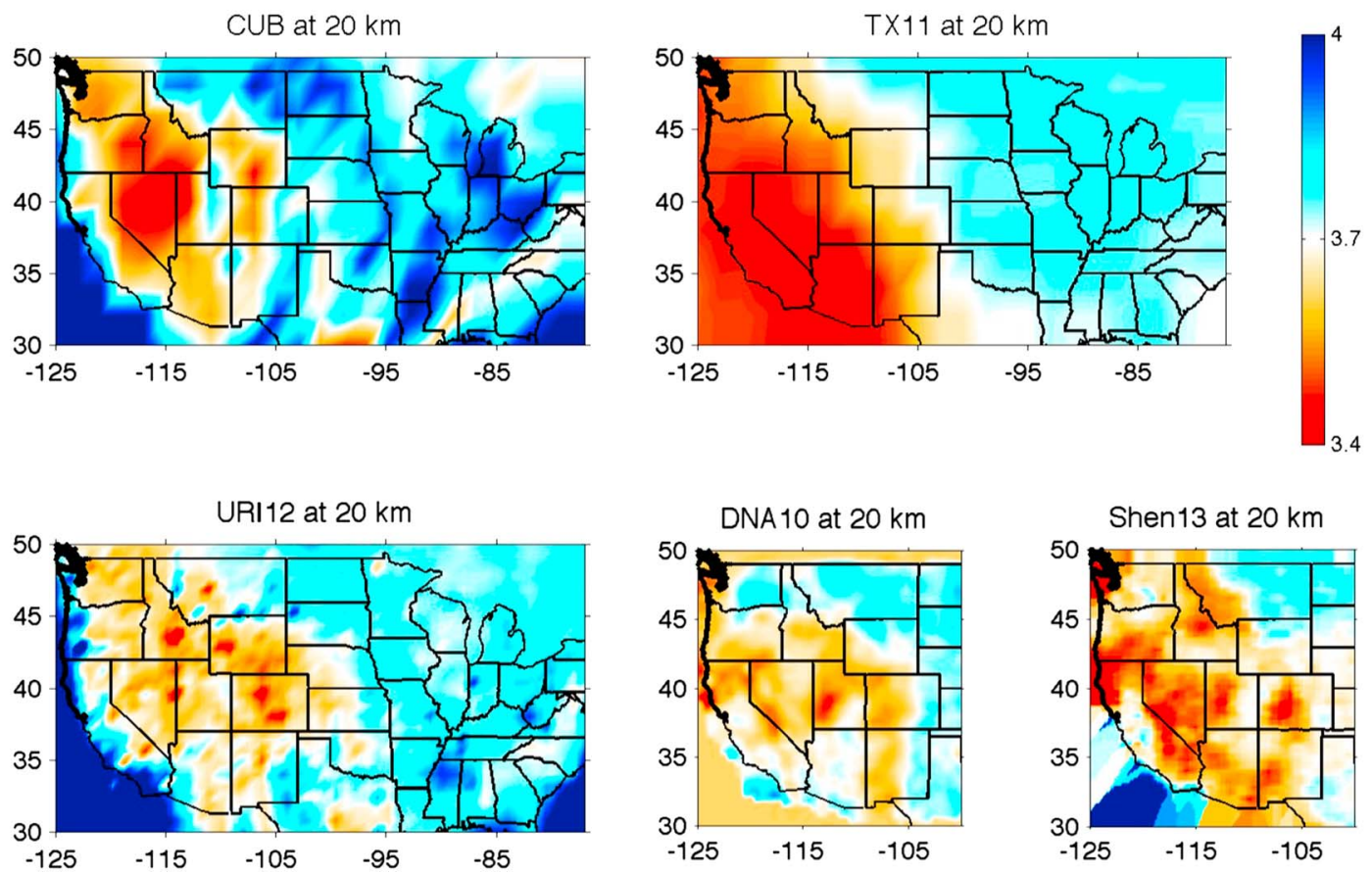

Figure 1. Shear wave velocity models for model accuracy validation in this study at depth of $20 \mathrm{~km}$. CUB, TX11 and URI12 cover the entire U.S., while DNA10 and Shen 13 cover the western and central U.S. The five models share the same color scale in $\mathrm{km} / \mathrm{s}$.

models is to directly compare the observed and synthetic waveforms [e.g., Song and Helmberger, 2007; Qin et al., 2009; Bozdag and Trampert, 2010; Gao and Shen, 2012]. Using the simulation of full-wave propagation, Gao and Shen [2012] systematically validated four surface wave tomographic models in the Cascades [Shapiro and Ritzwoller, 2002; Yang et al., 2008; Gao et al., 2011; Porritt et al., 2011]. The results showed that none of the Cascade models is adequately accurate in the sense that the misfits between the observed and predicted seismic waves are much larger than the uncertainty of the observed waveform, indicating room for significant improvement in the Cascade models. This earlier work suggests that it is necessary to also assess and validate the existing velocity models of the United States in a systematic way.

This study differs from the work by Gao and Shen [2012] in a few ways. First, surface wave signals are extracted only from ambient seismic noise in Gao and Shen [2012], while in this study we also include surface waves from large regional earthquakes. Second, Gao and Shen [2012] focus on the crustal structures in the Cascades using short- to intermediate-period (7-50 s) waves. Here we validate models covering a much large geographical area from the crust to $\sim 100 \mathrm{~km}$ depth, using up to $75 \mathrm{~s}$ period waves. Third, all the models tested in Gao and Shen [2012] are constructed from surface wave tomographic methods. In this study, our selected models include ones resolved with both body wave and surface wave signals.

In the following, we first introduce the velocity models that are selected for the model validation. Then we briefly present the data quality from ambient seismic noise and regional earthquakes and discuss wave propagation simulation. The phase delays and cross-correlation coefficients at multiple-frequency bands allow us to systematically and quantitatively compare these models.

\section{Models}

We select five shear wave velocity models (Figures 1 and 2). Three of them cover the entire U.S. and two the western and central U.S. Among these five models, one is resolved from shear wave tomography (an update of Grand [2002]), two from surface wave tomography [Shapiro and Ritzwoller, 2002; Shen, 2012], one from joint inversion of body wave travel times and surface wave dispersions [Obrebski et al., 2011], and one from the joint inversion of receiver functions and surface wave signals [Shen et al., 2013]. Our criterion for the model 

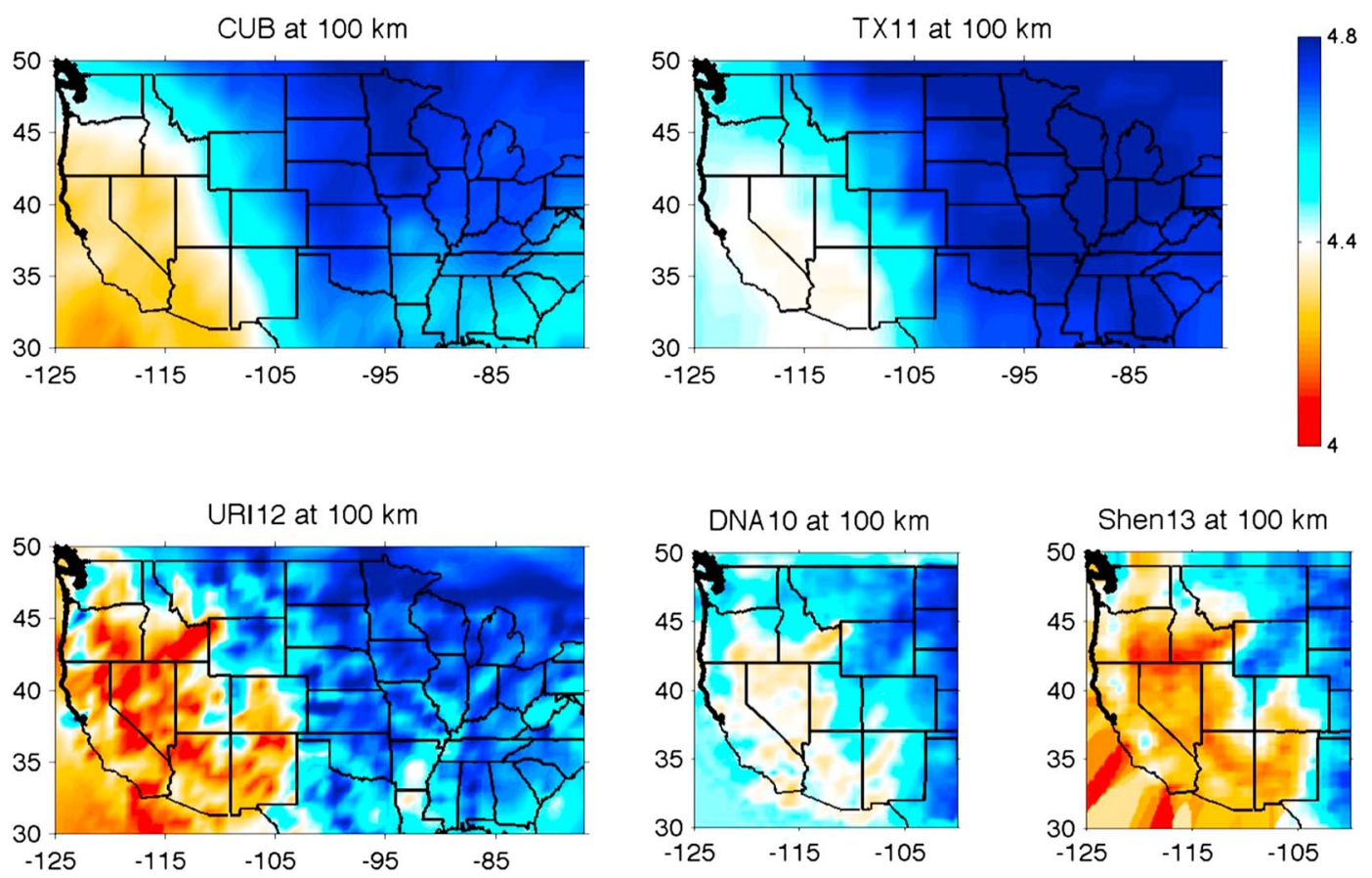

Figure 2. Same as Figure 1 except at depth of $100 \mathrm{~km}$.

selection among numerous existing models is that the model should provide absolute shear wave velocity from the surface to at least $200 \mathrm{~km}$ depth. This criterion is based on several considerations. First, the velocity perturbations resolved from teleseismic body wave tomography are not sensitive to the initial reference model [e.g., James et al., 2011], making it difficult to convert velocity perturbations to absolute values accurately. Second, Rayleigh waves (the observed waveforms used in model validation) are sensitive mostly to shear wave velocity, so uncertainties in conversion from $S$ wave velocity to $P$ wave velocity using a $V_{p} / V_{s}$ ratio cause relatively minor errors in Rayleigh waveforms. In contrast, systematic errors in the conversion from $P$ wave model to $S$ wave model may result in large deviation. In the following, we briefly describe the five selected models.

\subsection{CUB}

A $2^{\circ} \times 2^{\circ}$ global upper mantle shear wave velocity model by Shapiro and Ritzwoller [2002], based on fundamental mode surface wave group and phase velocities. The depth range of this model is from the Earth surface down to $\sim 400 \mathrm{~km}$, with a depth spacing of $4 \mathrm{~km}$. The model is downloaded from http://ciei.colorado. edu/ nshapiro/MODEL.

\section{2. $\mathrm{TX} 11$}

Grand [2002] derived a $2^{\circ} \times 2^{\circ}$ global shear wave tomography model (TX2000) from shear wave travel times, including multiple surface bounce arrivals. The depth range of the model is from the surface to the core-mantle boundary, with a depth spacing of $25 \mathrm{~km}$ within the top $1000 \mathrm{~km}$ depth. The model used in this study is an update of Grand [2002] in 2011 therefore named as TX11.

\subsection{URI12}

A $1^{\circ} \times 1^{\circ}$ U.S. shear wave velocity model by Shen [2012] from the full-wave tomography of intermediate- to long-period (37-400 s) empirical Green's functions (Rayleigh waves) extracted from ambient seismic noise recorded by $\sim 300$ selected stations in the conterminous U.S. The depth range of the model is from the surface to $\sim 1000 \mathrm{~km}$, and the vertical spacing increases with depth.

\subsection{DNA10}

A $0.2^{\circ} \times 0.2^{\circ}$ shear wave velocity model of the western and central U.S. by Obrebski et al. [2011] from a joint inversion of body wave travel times and surface wave phase velocities. This model takes into account the 


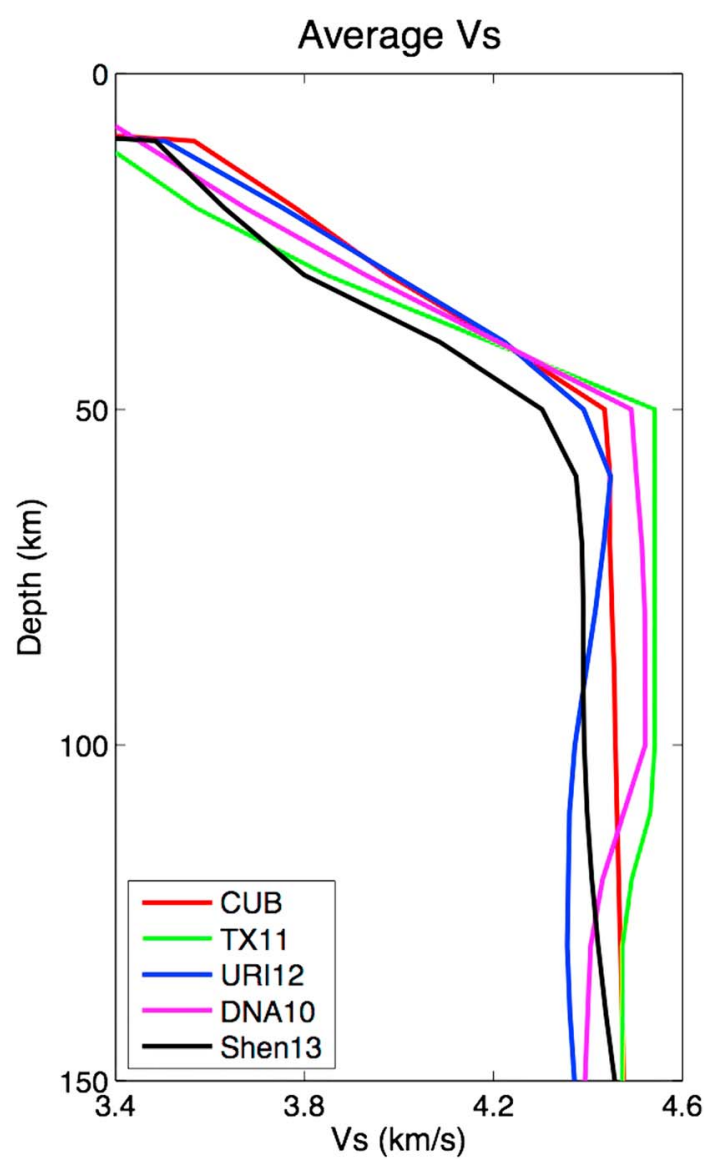

Figure 3. Average shear wave velocity (in $\mathrm{km} / \mathrm{s}$ ) of the five models within the western and central U.S. (that is, the study area of DNA10 and Shen13). Deeper than $50 \mathrm{~km}$, the shear wave velocity varies within a wide range among these models. variation of crust thickness within the study area. The depth range of the model is from the surface to $1000 \mathrm{~km}$, with a depth spacing of $25 \mathrm{~km}$.

\subsection{Shen 13}

A $0.25^{\circ} \times 0.25^{\circ}$ shear wave velocity model of the western and central U.S. by Shen et al. [2013] from a joint inversion of receiver functions and surface wave dispersion measurements. The depth range of the model is from the surface to $200 \mathrm{~km}$, with a depth spacing of $2 \mathrm{~km}$. Models of TX11, DNA10, and Shen 13 are available at Incorporated Research Institutions for Seismology (IRIS) Earth Model Collaboration (http://www.iris. edu/dms/products/emc-earthmodels/).

For all of the models, the western U.S. has relatively lower shear wave velocities than the eastern U.S. (Figures 1 and 2). Particularly, the patterns of URI12, DNA10, and Shen 13 are consistent with each other. Nevertheless, the magnitudes of these five shear wave models vary within a wide range (Figures 1-3), especially at depths greater than $50 \mathrm{~km}$. The difference in the average $V_{s}$ within the western and central U.S. is up to $\sim 0.3 \mathrm{~km} / \mathrm{s}$ (Figure 3). The average $V_{s}$ of Shen13 is much lower compared to

other models from the midcrust to $\sim 80 \mathrm{~km}$ depth, while at depths greater than $100 \mathrm{~km}$, URI12 has the lowest average $V_{s}$. TX11 has the highest $V_{s}$ within the depth range of $50-120 \mathrm{~km}$. The average velocity variations of DNA10 and TX11 show very similar trend at depths greater than $50 \mathrm{~km}$, with DNA10 relatively slower than TX11 at corresponding depths. The differences observed among these models result from different tomographic methods and seismic data sets. We convert $S$ wave velocity to $P$ wave velocity with a $V_{p} / V_{s}$ ratio of 1.74 in the crust [Brocher, 2005] and the empirical relationship of $V_{p}$ and $V_{s}$ in the International Association of Seismology and Physics of the Earth's Interior 91 mantle at the corresponding depths [Kennett et al., 1995]. The density is calculated as a function of $V_{p}$ [Christensen and Mooney, 1995].

None of the selected models provides a self-consistent attenuation structure, although the effects of wave dissipation may have significant effects on waveforms [e.g., Bozdag and Trampert, 2010; Savage et al., 2010], especially at depths greater than $100 \mathrm{~km}$ [Dalton et al., 2008]. As dissipation is less in the lithosphere, to minimize the complexity related to attenuation, we limit the comparison of phase delays to surface waves with periods up to $75 \mathrm{~s}$, which sample mostly the less attenuative crust and mantle lithosphere. Despite the severe limitations in the selection of the models and the data used in comparison, this study provides a direct and quantitative, though incomplete, assessment of the models in predicting seismic waveforms.

\section{Data and Method}

In this study, we use both the continuous seismic data from 1995 to 2012 and large $(M>=5.0)$ regional earthquake records from 2007 to 2012 for the model validation. All the data are requested from the IRIS Data Management Center, including ANZA Regional Network (AZ), Berkeley Digital Seismograph Network 

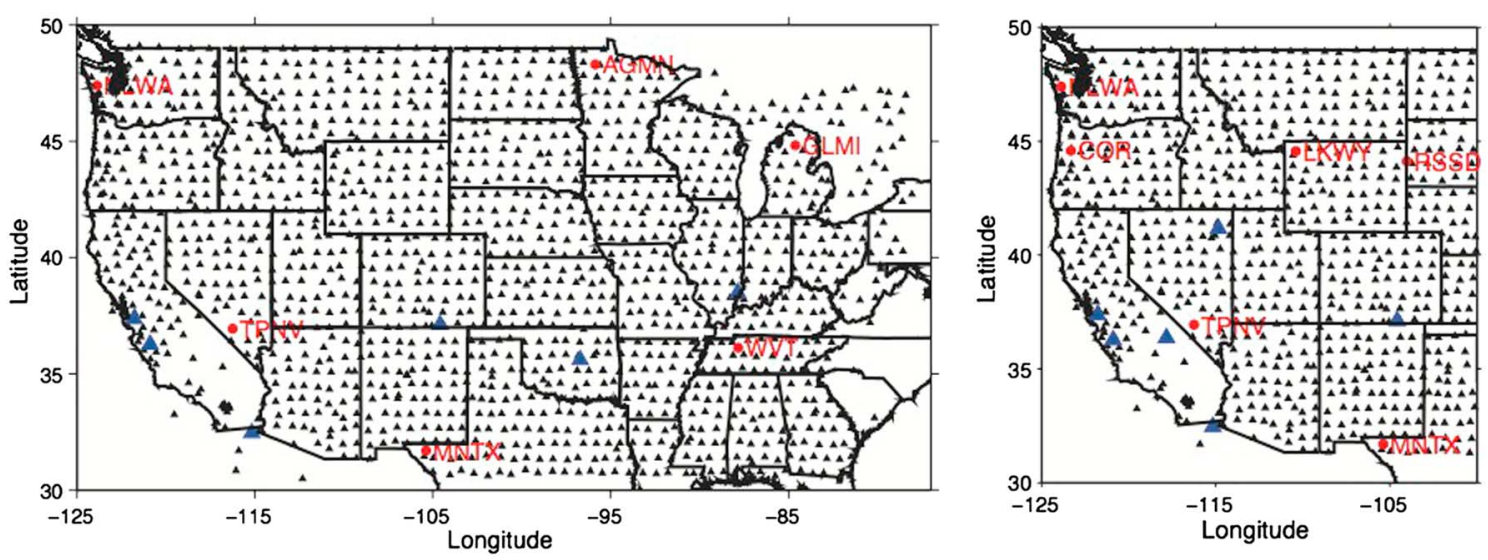

Figure 4. Distribution of seismic stations (black triangles), virtual source locations (red dots), and regional earthquakes (blue triangles) for (left) the entire U.S. area and (right) the western and central U.S. area.

(BK), California Institute of Technology Regional Seismic Network (CI), the Global Seismograph Network (IU), Network of Autonomously Recording Seismographs Array (NR), USArray Transportable Array (TA), the United States National Seismic Network (U.S.), and the Pacific Northwest Regional Seismic Network (UW). The instrument sensors are Streckeisen STS-2 or Güralp CMG-3 T types. The number of seismic stations used in this validation study is over 1500 for CUB, TX11, and URI12 (black triangles in Figure 4a) and 850 for DNA10 and Shen13 (black triangles in Figure 4b). The empirical Green's functions (EGF) between the station pairs are retrieved from the vertical-to-vertical component cross correlation of ambient noise. Prior

(a) Virtual source to receivers

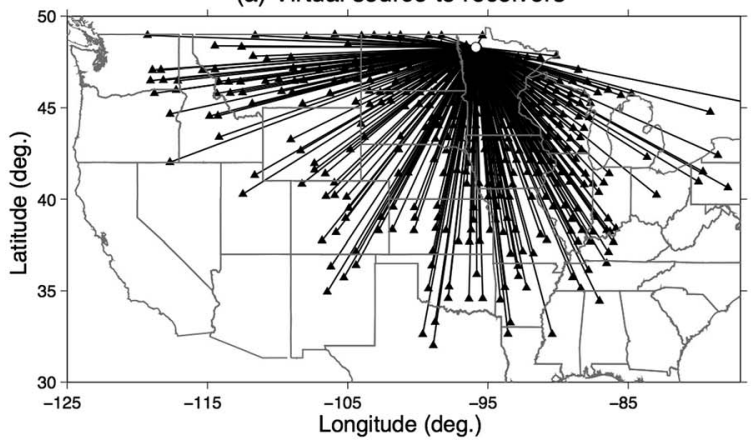

(b) EGFs at periods of $50-100 \mathrm{~s}$

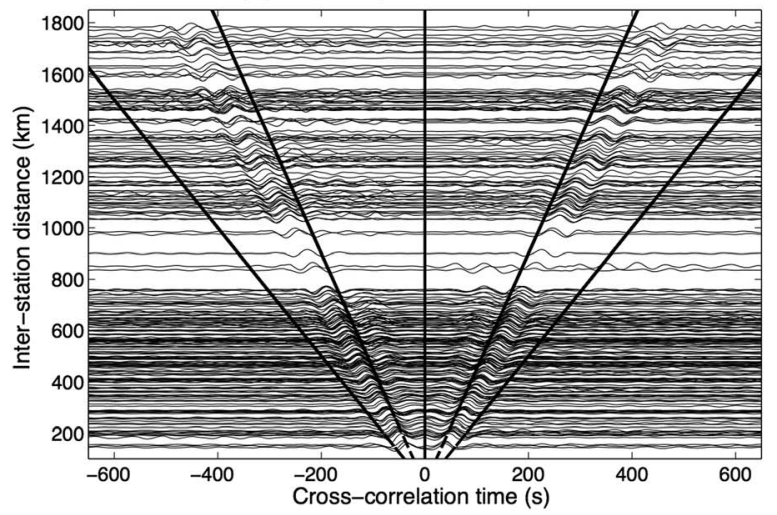

(c) EGFs at periods of $15-50 \mathrm{~s}$

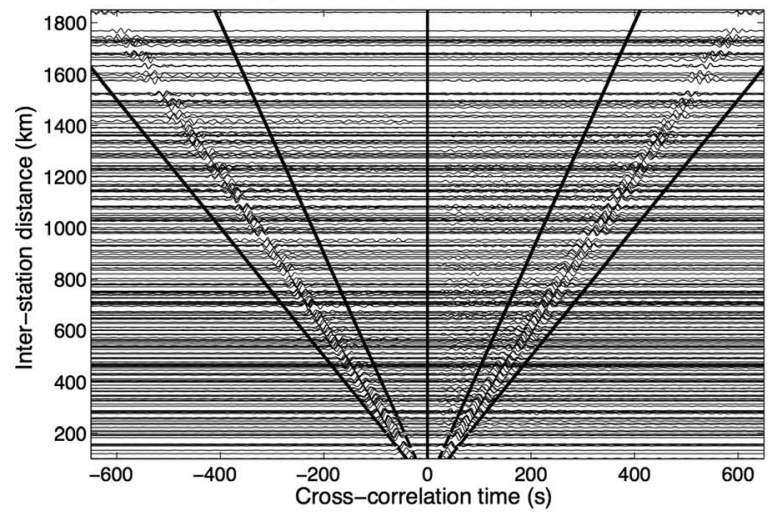

Figure 5. Example of empirical Green's functions (EGF) from one virtual source to all the receivers. (a) Raypath from the virtual source to all the other stations and ( $b$ and c) EGFs, sorted in terms of the interstation distance, are filtered at periods of 50-100 s and 15-50 s, individually. The black lines outline the surface wave signal window defined by the group velocity at $2.5 \mathrm{~km} / \mathrm{s}$ and $4.5 \mathrm{~km} / \mathrm{s}$. 
Table 1. Coordinates of "Virtual" sources in the Full-Wave Ambient Noise Tomography (Red Dots in Figure 4)

\begin{tabular}{lcc} 
Virtual Sources & Latitude $\left({ }^{\circ} \mathrm{C}\right)$ & Longitude $\left({ }^{\circ} \mathrm{C}\right)$ \\
\hline IU COR & 44.59 & -123.30 \\
IU RSSD & 44.12 & -104.04 \\
IU WVT & 36.13 & -87.83 \\
U.S. AGMN & 48.30 & -95.86 \\
U.S. GLMI & 44.82 & -84.62 \\
U.S. LKWY & 44.57 & -110.40 \\
U.S. MNTX & 31.70 & -105.38 \\
U.S. NLWA & 47.39 & -123.87 \\
U.S. TPNV & 36.95 & -116.25 \\
\hline
\end{tabular}

then sum the normalized signals into frequency-time-normalized waveform. We also eliminate the time segments of large $(M>5.5)$ earthquakes. To increase the signal-to-noise ratio, we stack daily cross correlations for each station pair. The EGFs are then recovered as the negative time derivative of the stacked cross correlations [e.g., Sabra et al., 2005; Snieder, 2004]. In addition, we obtain the monthly stacks of cross correlations, whose variations provide estimates of the uncertainties of EGFs and their travel times. The EGFs provide high-quality surface waves within the periods used in this validation study (15-75 s; Figure 5). To validate the models in a systematic way, we choose six widely distributed stations as "virtual sources" (red dots in Figure 4; Table 1) and all others as receivers. We also select six regional earthquakes (blue triangles in Figure 4; Table 2). The procedure to process the earthquake data involves removal of instrument response and obtaining a uniform sample rate of 1 point per second. The earthquakes provide high-quality seismic waveforms within the frequency bands of our interest (Figure 6).

To equate EGFs with Green's functions of the Earth, a uniform distribution of noise sources around the seismic stations and zero attenuation are required [e.g., Wapenaar, 2004; Wapenaar and Fokkema, 2006; Snieder, 2007]. These conditions are usually not strictly satisfied in seismic ambient noise [e.g., Yang and Ritzwoller, 2008]. For our study area, most of the ambient noise comes from the Pacific Ocean and the northern Atlantic Ocean. On the other hand, it has been suggested that the nonuniformity of noise sources significantly affects the surface wave amplitude [Tsai and Moschetti, 2010] but not the velocity [Snieder, 2004]. Numerical experiments show that the nonuniform distribution of noise sources leads to less than $0.5 \%$ error in travel times and phase velocity [Yang and Ritzwoller, 2008]. This level of error is much less than the lateral velocity variations in the Pacific Northwest [e.g., Porritt et al., 2011; Gao and Shen, 2012] and the differences among the models tested in this study (up to 7\%; Figure 3). In the following, we consider the effects of nonuniform noise source distribution on travel times secondary to those of the Earth structure and EGF a close approximation to the surface wave portion of the Green's function of the Earth.

We simulate wave propagation in the 3-D spherical Earth structure with a 3-D nonstaggered grid, finite difference method [Zhang et al., 2012]. The horizontal grid spacing is $\sim 3 \mathrm{~km}$ along geographic longitude and latitude. The vertical grid spacing is depth dependent with finer grids in the crust, $\sim 1.0 \mathrm{~km}$ near the surface, and increases to $5 \mathrm{~km}$ at $100 \mathrm{~km}$ depth. Such a grid is sufficient to accurately simulate wave propagation at

Table 2. Regional Earthquakes Used in the Model Validation From Global CMT Solutions (http://www.globalcmt.org/CMTsearch.html) ${ }^{\text {a }}$

\begin{tabular}{lcccccc} 
Earthquakes (Centroid Time) & Latitude $\left({ }^{\circ} \mathrm{C}\right)$ & Longitude $\left({ }^{\circ} \mathrm{C}\right)$ & Depth $(\mathrm{km})$ & $M_{w}$ & $T(\mathrm{~s})$ & Moment Tensor $(\mathrm{dyn} \mathrm{cm})$ \\
\hline 31/10/2007 03:04:59 & 37.37 & -121.78 & 13.9 & 5.6 & 1.5 & $(-0.033,-2.53,2.56,0.209,0.417,0.836) \times 10^{24}$ \\
21/2/2008 14:16:10 & 41.16 & -114.85 & 13.5 & 6.0 & 2.5 & $(-1.27,0.198,1.07,0.069,0.256,0.61) \times 10^{25}$ \\
18/4/2008 09:37:03 & 38.49 & -87.86 & 26.9 & 5.4 & 1.3 & $(-0.096,1.420,-1.330,-0.064,-0.046,1.140) \times 10^{24}$ \\
1/10/2009 10:01:28 & 36.37 & -117.83 & 14.8 & 5.1 & 0.9 & $(-0.344,-5.390,5.730,-0.111,-1.370,2.950) \times 10^{23}$ \\
30/12/2009 18:49:01 & 32.46 & -115.17 & 14.7 & 5.9 & 2.1 & $(-0.088,-0.669,0.757,0.095,0.050,0.349) \times 10^{25}$ \\
14/9/2010 10:52:22 & 32.14 & -115.20 & 14.7 & 5.0 & 0.8 & $(-1.580,-3.260,4.840,0.515,-0.683,-0.467) \times 10^{23}$ \\
23/8/2011 05:46:22 & 37.12 & -104.59 & 12 & 5.3 & 1.1 & $(-1.210,0.025,1.190,0.119,-0.383,0.302) \times 10^{23}$ \\
6/11/2011 03:53:13 & 35.61 & -96.72 & 12 & 5.7 & 1.8 & $(-0.463,4.610,-4.150,-0.063,-0.171,-1.490) \times 10^{24}$ \\
21/10/2012 06:55:14 & 36.27 & -120.89 & 12 & 5.4 & 1.2 & $(0.132,-1.180,1.050,-0.308,0.295,0.888) \times 10^{24}$ \\
\hline
\end{tabular}

${ }^{a}$ The estimated half duration $(T)$ is used to calculate source time function (see example in Figure 8 ). The focal mechanism listed in column 7 is in the order of Mrr, Mtt, Mpp, Mrt, Mrp, and Mtp. 
(a) Earthquake to receivers

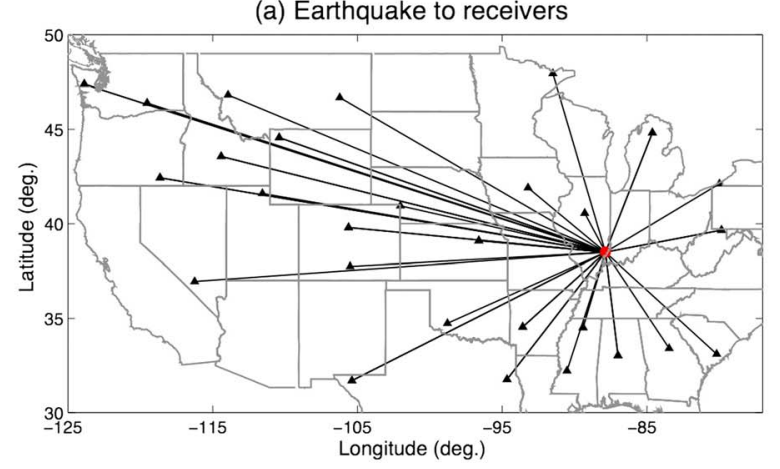

(b) $50-100 \mathrm{~s}$

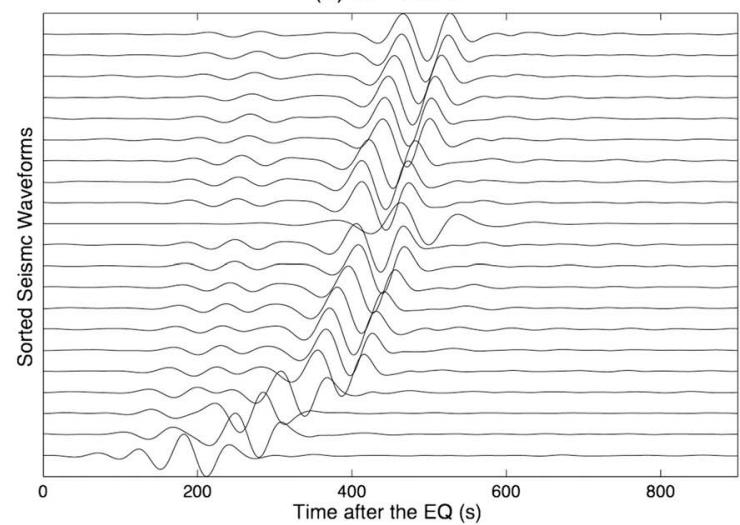

(c) $15-50 \mathrm{~s}$

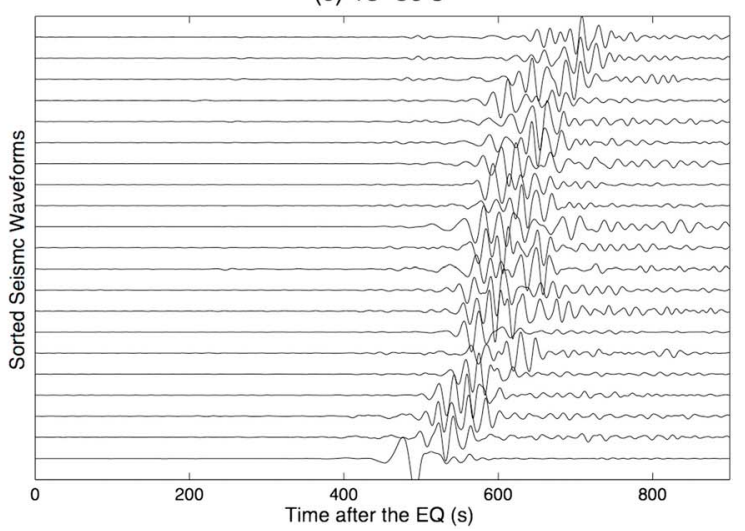

Figure 6. Example of a regional earthquake (18 April 2008 09:37:03) recorded by the seismic stations. (a) The distribution of the earthquake (red dot) and the selected seismic stations (black triangles). See the detailed earthquake information in Table 2. (b and c) Recorded seismic waveforms filtered at 50-100 s and 15-50 s, individually. The $y$ axis in Figures $6 b$ and $6 c$ is sorted by the distance from the epicenter to the station.

$15 \mathrm{~s}$ and longer periods [see Zhang et al., 2012]. To maintain numerical stability, we use a time step of $0.15 \mathrm{~s}$. The total wave propagation time in simulation is $2000 \mathrm{~s}$, as the longest distance between stations is about $5000 \mathrm{~km}$. To calculate Green's functions, we use a Gaussian pulse with a half width of $3 \mathrm{~s}$ as the source time

(a) Ambient noise STF

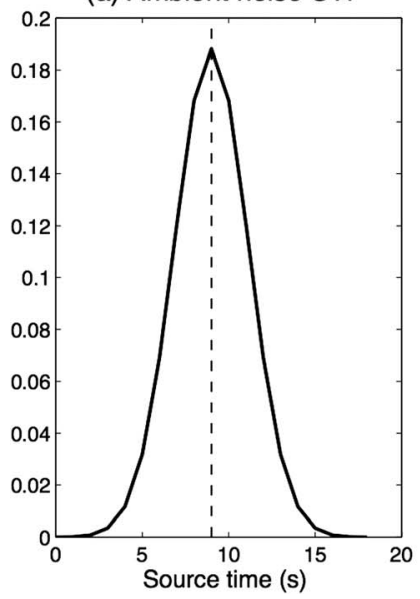

(b) EGFs at periods $10-25 \mathrm{~s}$

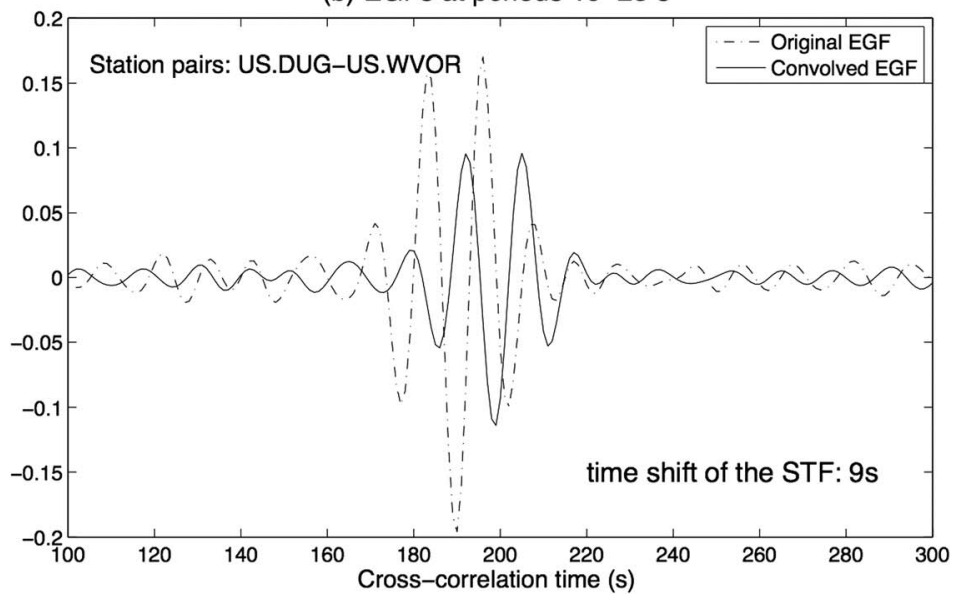

Figure 7. Source time function (STF) used in the wave simulation for ambient noise tomography. (a) The half width of the Gaussian source time function is $3 \mathrm{~s}$, and the time shift of the STF from zero is $9 \mathrm{~s}$. To account for the initial time shift of the simulated waveforms and the finite-frequency nature of the STF, we need to convolve the EGF with the STF. (b) Example of convolution of EGF with the source time function, filtered at 10-25 s period. As we can see, the convolved EGF has been shifted $9 \mathrm{~s}$ forward. 
(a) EQ STF in simulation

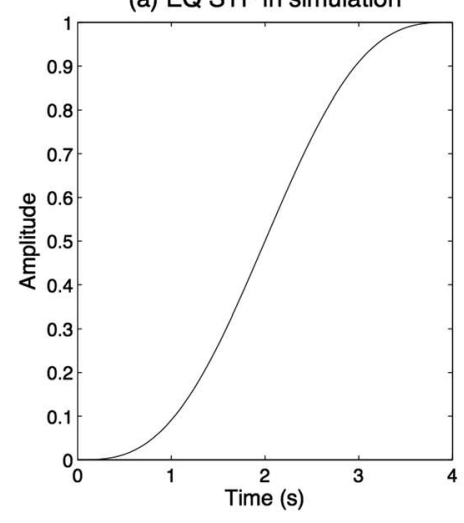

(d) Estimated EQ STF

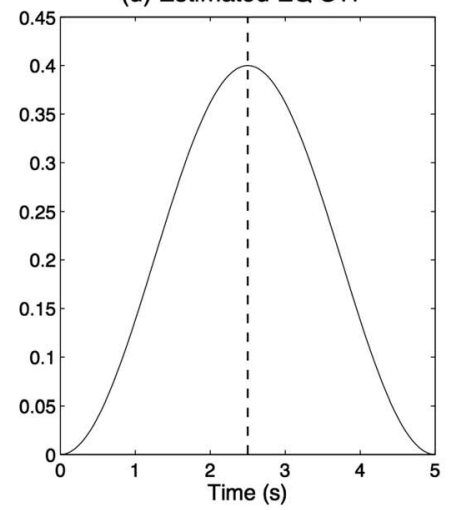

(b) Derivative of (a)

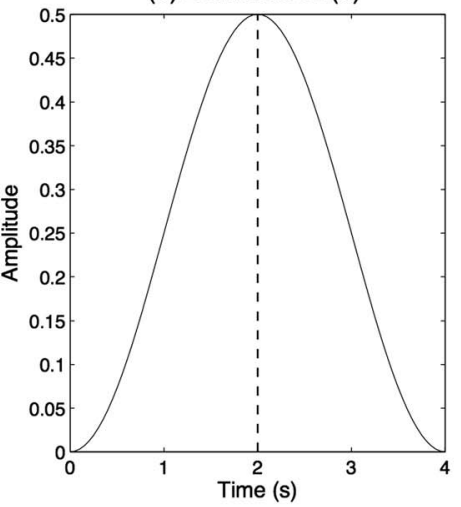

(c) Observed waveform filtered at 10-25 s

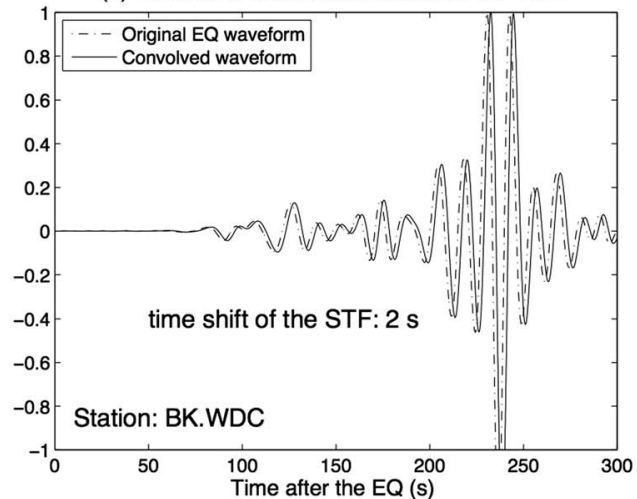

(e) Synthetic waveform filtered at $10-25 \mathrm{~s}$

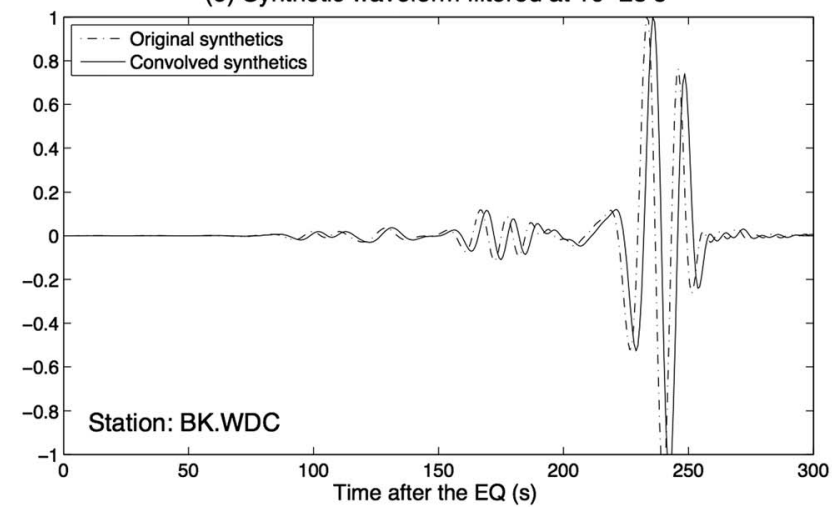

Figure 8. (top) Source time function used in the wave simulation for earthquakes. (a) The source time function in the earthquake simulation is a bell integral step function, with the width of $4 \mathrm{~s}$. (b) The derivative of the source step function. (c) Convolution of observed earthquake waveform by station BK WDC with the source function in Figure $8 \mathrm{~b}$, filtered at 10-25 s period, which shifts the waveform $2 \mathrm{~s}$ forward. (bottom) Estimated source time function for the regional earthquake at 21 February 2008 14:16:10. (d) The earthquake source time function is estimated with the half duration from the global CMT solution as listed in Table 2.

(e) Convolution of synthetic waveform with the function in Figure $8 \mathrm{~d}$, which shifts the synthetics $2.5 \mathrm{~s}$ forward.

function (Figure 7a). To simulate the regional earthquakes, we use the global centroid moment tensor (CMT) solutions (see Table 2) [Dziewonski et al., 1981; Ekström et al., 2012] for the earthquake source timing, location, and moment tensors. For computational reason, we use a bell integral function with the full width of $4 \mathrm{~s}$ (Figure 8a) as the earthquake source time function in the simulation (see adjustments for different earthquake source time functions below). The 3-D wave simulation is executed on a Linux cluster with 17 nodes (each with 24 CPU cores). It takes about $27 \mathrm{~h}$ per simulation on four nodes. No anisotropy (see discussion by Gao and Shen [2012]) and attenuation are considered in the wave simulation. We assume minor effect of attenuation on the travel times of surface waves at shallow depths [e.g., Bozdag and Trampert, 2010; Savage et al., 2010].

In this study, we compare the surface wave signals extracted from ambient noise and earthquakes with synthetic waveforms. Prior to comparing the EGFs and synthetics, we first split the EGFs into positive (causal) and negative (acausal) time lags. To account for the finite-frequency nature and initial time shift of the simulated waveforms, we then convolve the observed EGFs and earthquake waveforms with the corresponding source time functions used in wave simulations for ambient noise and earthquake data, respectively (Figure 7 and Figures $8 \mathrm{a}-8 \mathrm{c}$ ). In addition, for earthquake data, we also convolve synthetics with the source time function from the global CMT solutions (Figures $8 \mathrm{~d}$ and $8 \mathrm{e}$ and Table 2 ) to equalize the effects of finite source times in nature and simulation. The source time-equalized waveforms from empirical and synthetic Green's functions are

$$
\begin{aligned}
& u_{d}(t)=\widetilde{G}(t) * \Lambda_{s}(t) \\
& u_{s}(t)=G(t) * \Lambda_{s}(t)
\end{aligned}
$$


(a) $35-75 \mathrm{~s}$

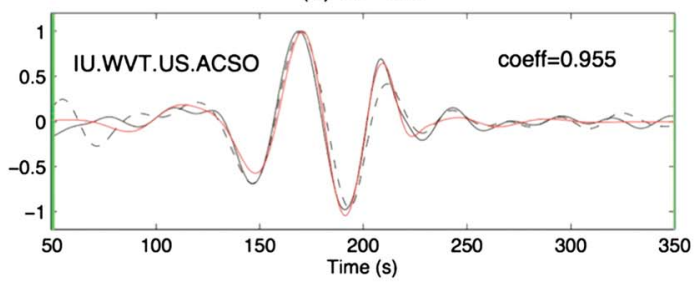

(b) 25-50s

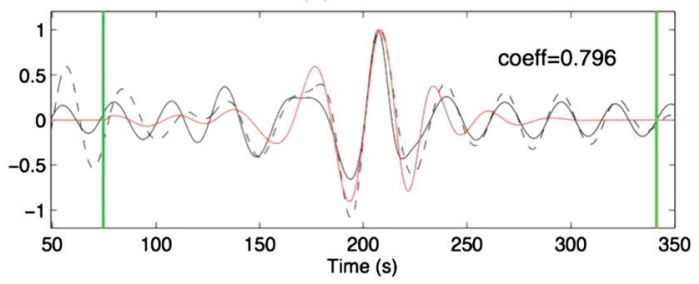

(c) $15-35 s$

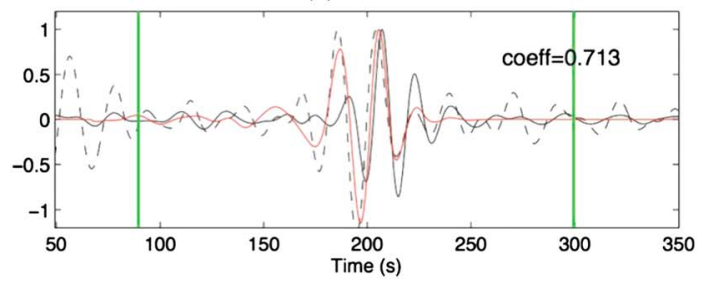

(d) $35-75 \mathrm{~s}$

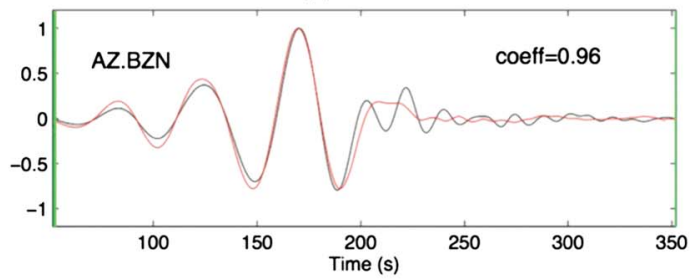

(e) 25-50s

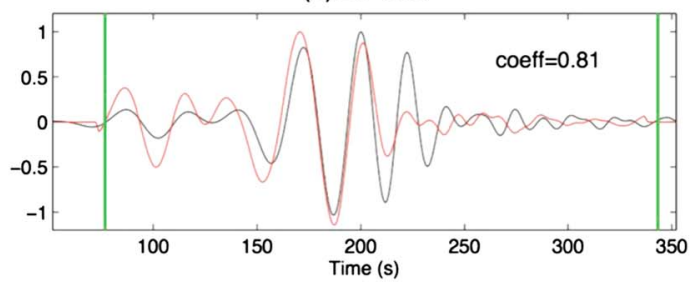

(f) $15-35 s$

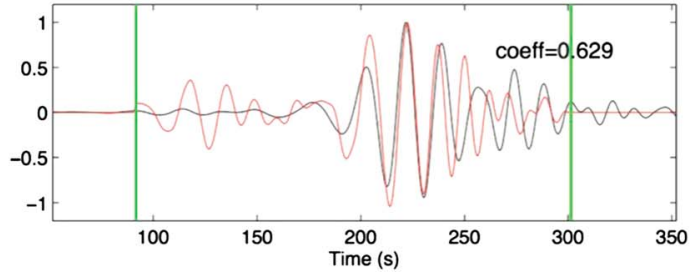

Figure 9. Comparison of observed (black) and synthetic (red) waveforms for (left, station pair of IU WVT U.S. ACSO) ambient noise and a (right, 31 October 2007 03:04:59) regional earthquake recorded by station AZ BZN with the model of URI12. The solid and dashed black lines on the left correspond to the causal and acausal parts of the EGF, respectively. The time window (defined by the green lines) is frequency dependent (see the text for details). The cross-correlation coefficients are labeled within each panel.

where $u_{d}(t)$ and $u_{s}(t)$ are the observed and synthetic waveforms, respectively, $\widetilde{G}(t)$ is the empirical Green's function extracted from ambient noise, $G(t)$ is the Green's function, and $\Lambda_{s}(t)$ is the source time function used in numerical simulation. Similarly, the equalized earthquake waveforms are

$$
\begin{aligned}
& u_{d}(t)=G(t) * \Lambda_{e}(t) M * \Lambda_{s}(t) \\
& u_{s}(t)=G(t) * \Lambda_{s}(t) M * \Lambda_{e}{ }^{\prime}(t)
\end{aligned}
$$

where $\Lambda_{e}{ }^{\prime}(t)$ is the approximation of the earthquake source time function $\left(\Lambda_{e}(t)\right)$ in the global CMT solution and $M$ is the earthquake moment tensor.

After source time equalization, we then cross correlate the positive- and negative-time-lag EGFs or observed earthquake waveforms with the corresponding synthetics using the MATLAB function xcorr within multiple-period bands, ranging from $35-75 \mathrm{~s}$ and $25-50 \mathrm{~s}$ to $15-35 \mathrm{~s}$ (Figure 9). These wave periods are much longer than the earthquake source time function (Table 2), so the higher-order complexity in earthquake source time functions is negligible, and the source time convolution in equations (1)-(4) amounts to a time shift in waveforms. We also experimented with measuring the phase delays in narrower band pass filters (15-25 s, 25-35 s, 35-50s, and 50-75 s). The results are similar to what are presented in Figures 10-12, so the use of narrower period bands does not change the pattern of phase delays, but does slightly increases the scattering of the measurements, reflecting the trade-off in the narrowness of the frequency band and the uncertainty of phase delay measurements. Note that for the comparison of the EGFs and synthetics, we mainly consider the phase arrivals, which are relatively stable, rather than the accuracy of the waveforms, which can change significantly due to the uneven source distribution and normalization methods used at the data processing.

Both the observed and synthetic data are filtered with the zero-phase digital filtering (performed with the MATLAB function filtfilt). To ensure high-quality signals, the source-receiver distance is required to be at least 1.5 wavelength and the signal-to-noise ratio of the seismic waveforms at least 10 . To avoid phase cycle 
(a) CUB: $35-75 \mathrm{~s}$

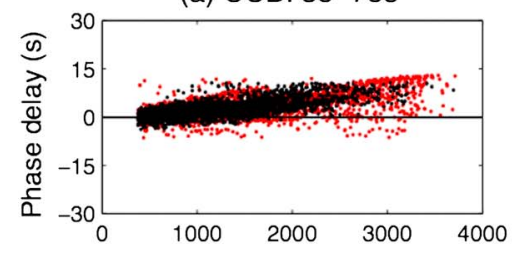

(d) TX11: 35-75s

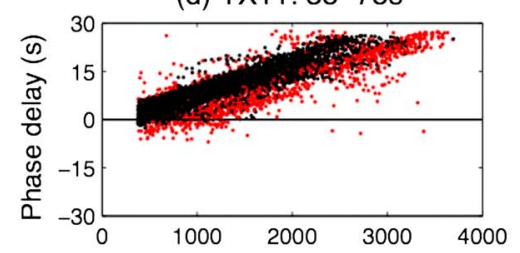

(g) URI12: 35-75s

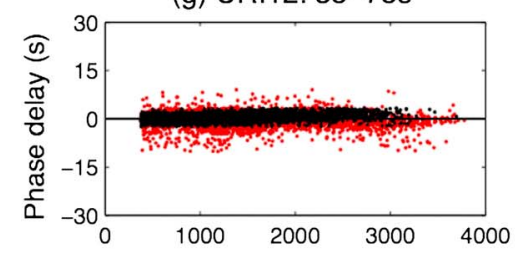

(j) DNA10: 35-75s

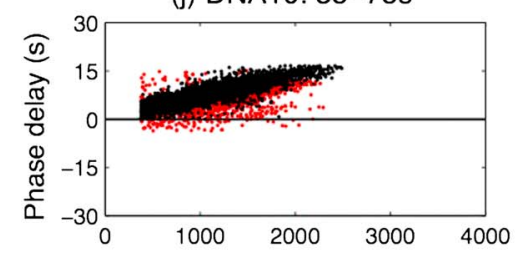

(m) Shen 13: 35-75s

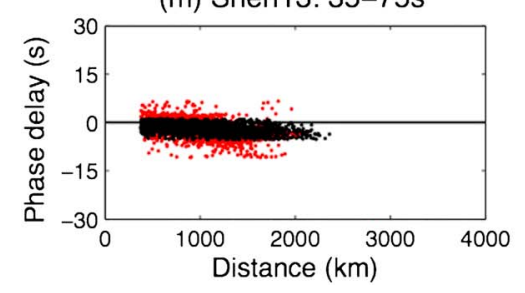

(b) 25-50s

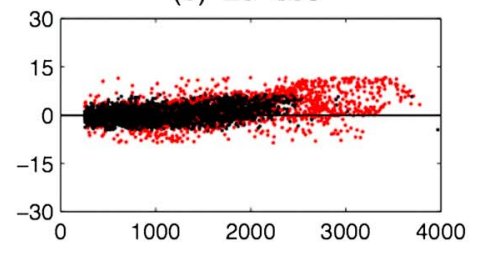

(e) $25-50 \mathrm{~s}$

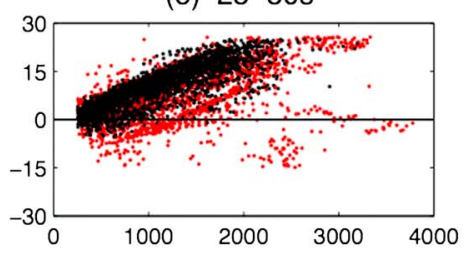

(h) 25-50s

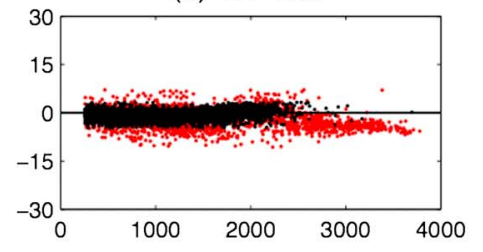

(k) 25-50s

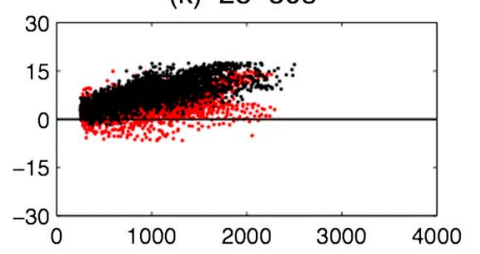

(n) 25-50s

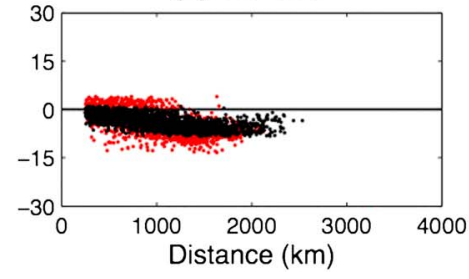

(c) $15-35 \mathrm{~s}$

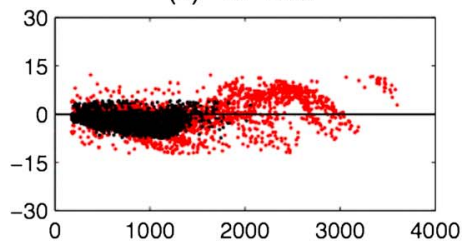

(f) $15-35 \mathrm{~s}$

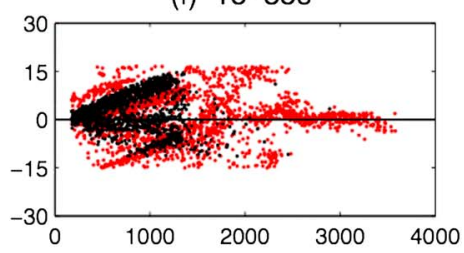

(i) $15-35 \mathrm{~s}$

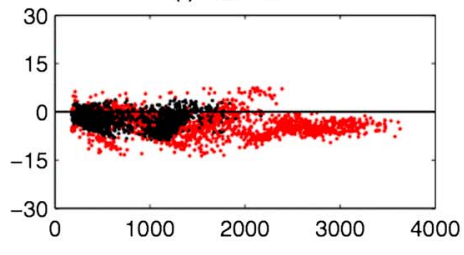

(I) 15-35s

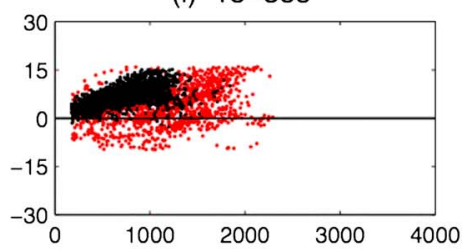

(o) $15-35 \mathrm{~s}$

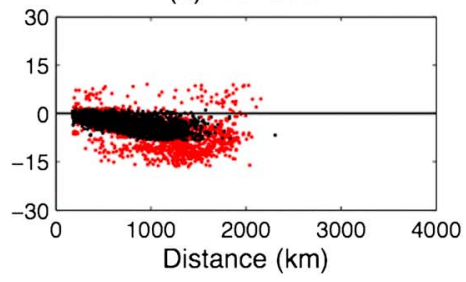

Figure 10. Phase delays versus source-receiver distance filtered at four period bands. Each row represents one model, and each column represents one period band. The black and red dots with outlines are measurements from ambient noise and regional earthquakes, individually. A positive linear trend indicates that the synthetics arrive earlier than the observations, which prefer a relatively slower Earth structure.

skipping, we restrict the maximum cross-correlation lag time to the lower period limit within each period range. The selection of the signal window, which is frequency dependent, is empirical based on our experience. We define the starting time of the signal window as the distance divided by a high-enough group velocity for the observed Rayleigh waves $(4.3 \mathrm{~km} / \mathrm{s})$ minus the upper period limit within each period range. The window length varies within 4-6 times of the upper period limit from the shorter- to longer-period bands to ensure capture of the main seismic arrivals. The phase delay time is the average of the measurements for the positive and negative time lags, which minimizes the effect of the instrument time shift, if it exists [Stehly et al., 2007]. We then shift the synthetics correspondingly in terms of amount of the phase delay and calculate the cross-correlation coefficient with the observed waveforms.

\section{Results and Discussion}

The measurements between the observations and synthetics for both ambient noise and regional earthquakes are shown and compared in three ways: phase delay versus interstation or source-receiver distance (Figure 10), histogram of phase delays (Figure 11), and histogram of cross-correlation coefficients (Figure 12). The mean and 
(a) CUB: $35-75 \mathrm{~s}$

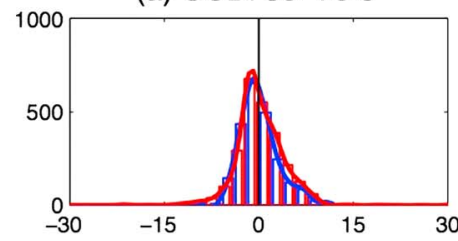

(d) TX11:35-75 s

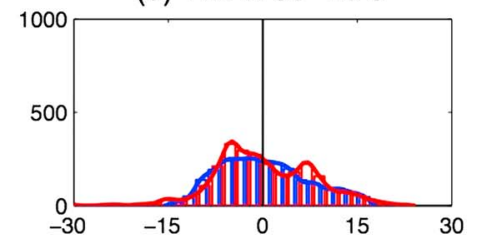

(g) URI12: $35-75 \mathrm{~s}$

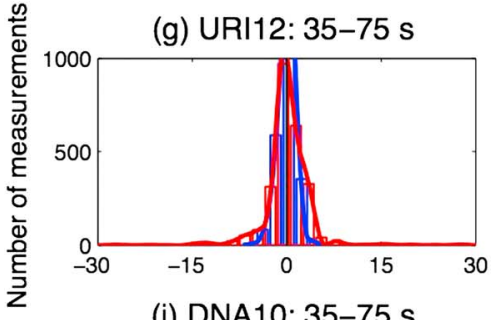

(j) DNA10: 35-75 s

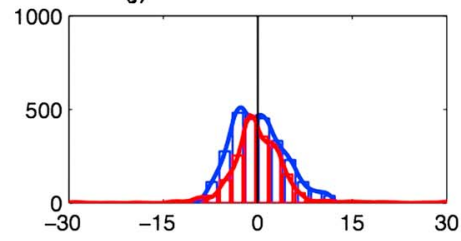

(m) Shen13: 35-75 s

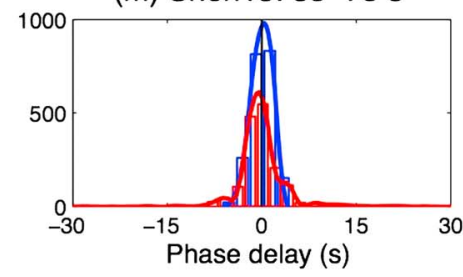

(b) 25-50 s

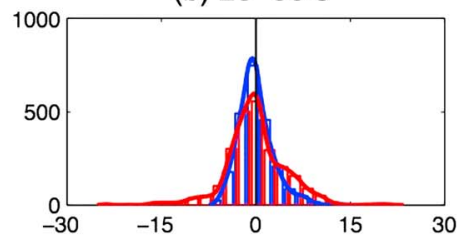

(e) 25-50 s

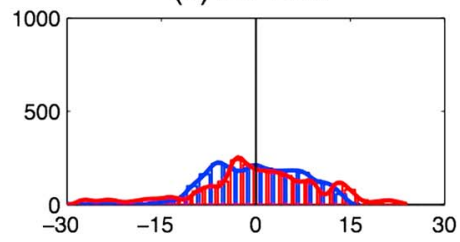

(h) $25-50 \mathrm{~s}$

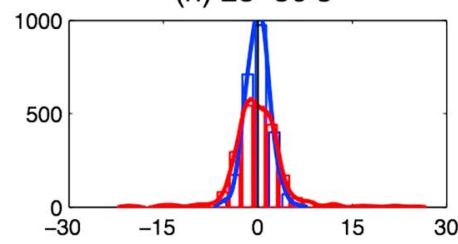

(k) 25-50 s

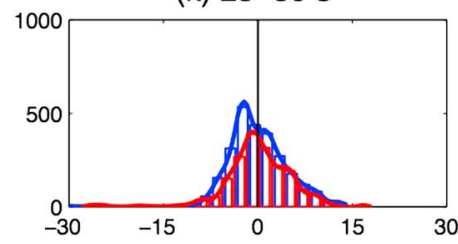

(n) $25-50 \mathrm{~s}$

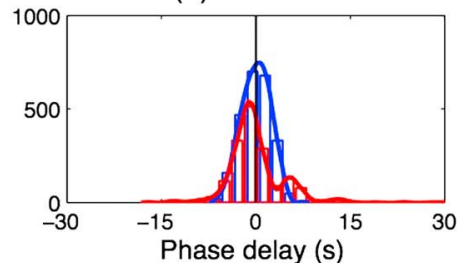

(c) $15-35 \mathrm{~s}$

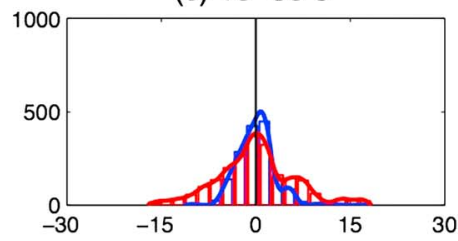

(f) $15-35 \mathrm{~s}$

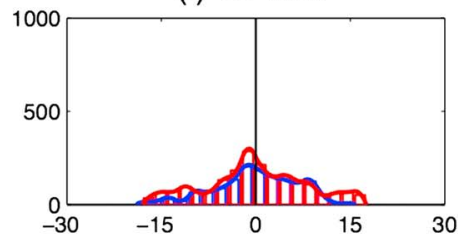

(i) $15-35 \mathrm{~s}$

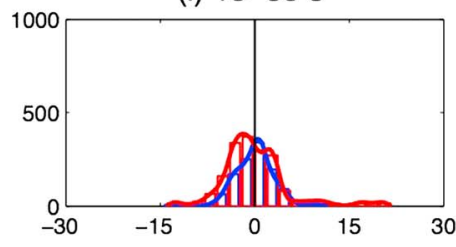

(l) $15-35 \mathrm{~s}$

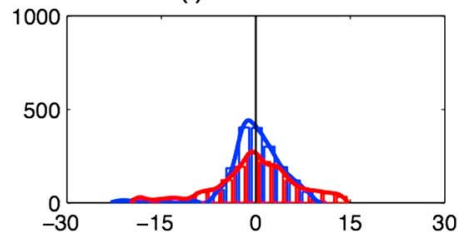

(o) $15-35 \mathrm{~s}$

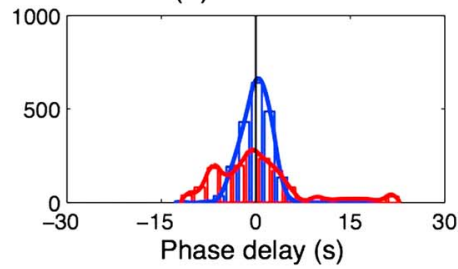

Figure 11. Histogram of phase delays after removing the linear trend. Blue: measurements from ambient noise and red: measurements from regional earthquakes.

standard deviation of the phase delays from ambient noise and regional earthquakes for the five models at each frequency range are listed in Table 3. An accurate model would result in nearly zero-phase delays and high cross-correlation coefficients between the synthetics and observations at all the frequency bands. A positive delay time in this study means that synthetic Rayleigh wave arrives earlier than observation; that is, the model is relatively faster than the real Earth structure. Phase delays from earthquakes appear to be more scattered than from ambient noise (Figures 10 and 11), which partly result from uncertainties of the earthquake source location, origin time, and moment tensors. For example, a $10 \mathrm{~km}$ mislocation of the hypocenter will result in about $3 \mathrm{~s}$ phase delay, assuming a $3.5 \mathrm{~km} / \mathrm{s}$ phase velocity. Meanwhile, statistically, the cross-correlation coefficients from regional earthquakes are higher than from ambient noise (Figure 12), which means a better match of synthetic waveforms with observations. This likely reflects the fact that the earthquake waveforms have higher signal-to-noise ratios than the waveforms extracted from ambient seismic noise (Figure 9). Nevertheless, in general, for each model, the trend of phase delay versus interstation or source-receiver distance is consistent between ambient noise and regional earthquakes.

\subsection{Models of CUB and TX11}

Phase delays from CUB and TX11 show an obvious positive linear trend with the source-receiver distances except at the shortest periods (Figures 10 and 11). This implies that these two models are, on average, too fast 
(a) CUB: $35-75 \mathrm{~s}$

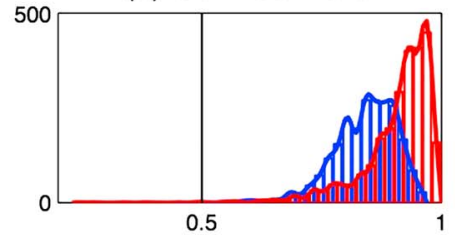

(d) TX11:35-75 s
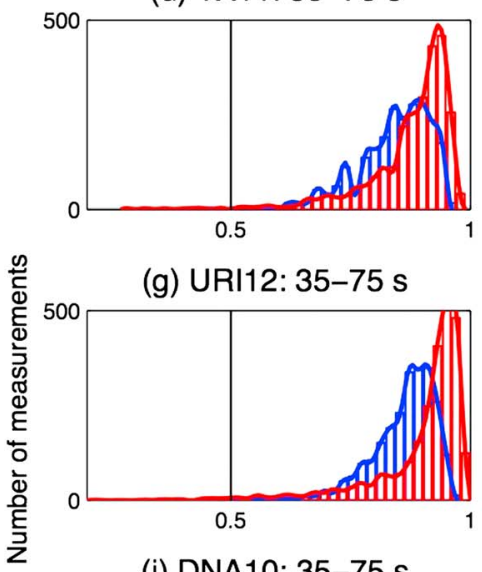

(j) DNA10: 35-75 s

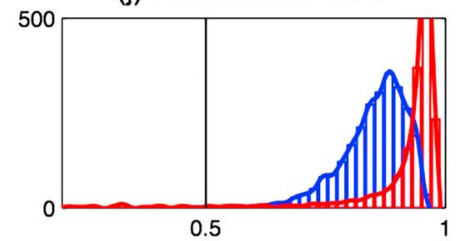

(m) Shen 13: 35-75 s

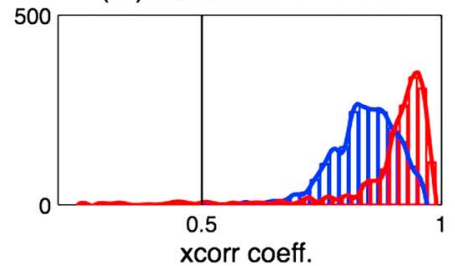

(b) 25-50 s

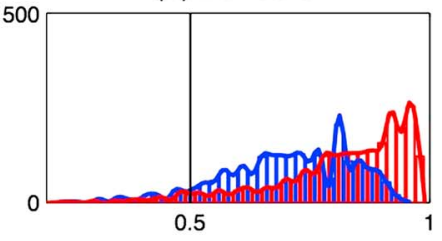

(e) 25-50 s

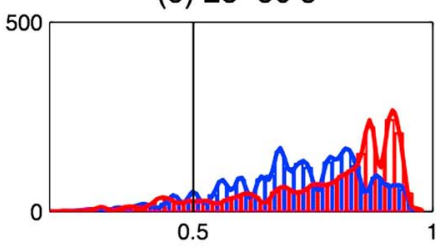

(h) 25-50 s

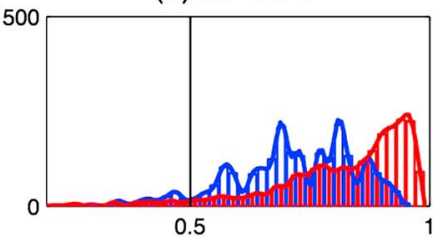

(k) 25-50 s

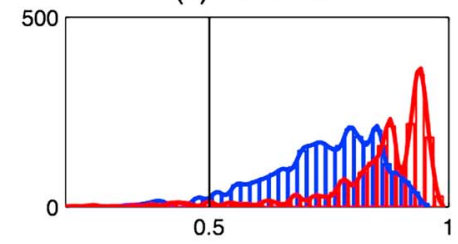

(n) 25-50 s

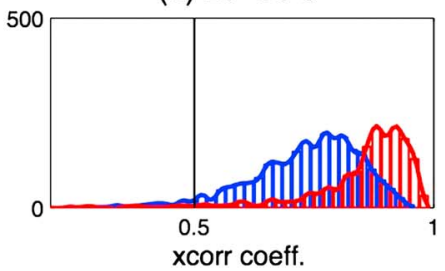

(c) $15-35 \mathrm{~s}$

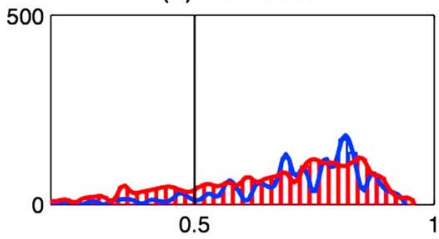

(f) $15-35 \mathrm{~s}$

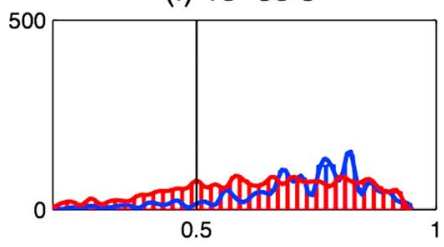

(i) $15-35 \mathrm{~s}$

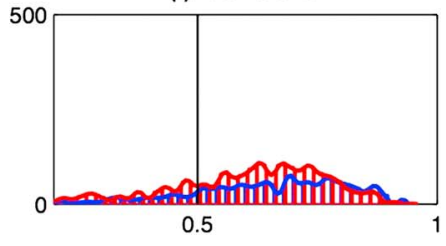

(I) $15-35 \mathrm{~s}$

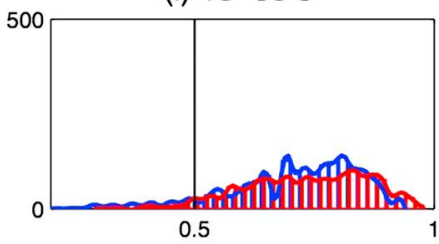

(o) $15-35 \mathrm{~s}$

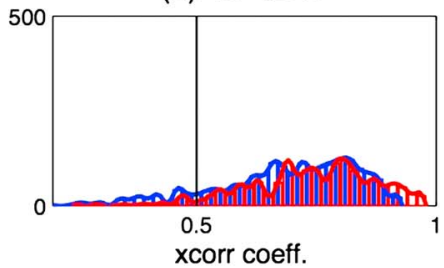

Figure 12. Histogram of cross-correlation coefficients. Blue: measurements from ambient noise and red: measurements from regional earthquakes.

for the real U.S. structure in the uppermost mantle and lower crust. In particular, TX11 has the highest average velocities in the uppermost mantle and lower crust among the five selected models (Figure 3). Measurements at short periods appear to be more scattered, especially from earthquakes, which may reflect the complex shallow crustal structure not present in the models. Distribution of cross-correlation coefficients (Figure 12)

Table 3. The Mean and Standard Deviation of the Phase Delays at Three Period Ranges for Five Models Tested in This Study ${ }^{\mathrm{a}}$

\begin{tabular}{lccccc} 
& CUB & TX11 & URI12 & DNA10 & Shen13 \\
\hline $35-75 \mathrm{~s}$ & $2.84 / 3.99$ & $10.88 / 12.68$ & $0.40 / 1.29$ & $7.95 / 8.78$ & $-1.96 / 2.48$ \\
& $3.53 / 4.86$ & $10.57 / 12.95$ & $-0.63 / 2.56$ & $5.76 / 6.64$ & $-2.42 / 3.69$ \\
$25-50 \mathrm{~s}$ & $0.48 / 2.35$ & $10.09 / 12.21$ & $-0.76 / 1.84$ & $7.75 / 8.70$ & $-3.69 / 4.27$ \\
& $1.48 / 4.01$ & $7.44 / 11.36$ & $-1.96 / 3.46$ & $4.58 / 6.15$ & $-4.89 / 6.01$ \\
$15-35 \mathrm{~s}$ & $-1.75 / 3.05$ & $2.19 / 6.15$ & $-2.48 / 3.61$ & $6.68 / 7.46$ & $-3.48 / 4.08$ \\
& $-0.23 / 4.92$ & $0.64 / 7.45$ & $-3.73 / 5.17$ & $3.63 / 6.42$ & $-5.63 / 7.45$ \\
\hline
\end{tabular}

\footnotetext{
${ }^{\mathrm{a}}$ For each model at one period range, the top row is from ambient noise, and the bottom row is from regional earth-
} quakes in the format of mean/standard deviation. 
shows that synthetic waveforms fit the observations better at longer periods than at shorter periods. This also indicates the poorly resolved crustal structure. By comparing the histogram of the cross-correlation coefficients from earthquakes and ambient noise (Figure 12), it appears that for both CUB and TX11, the synthetics fit the earthquake waveforms better than the EGFs within periods of 25-75 s.

\subsection{Model of URI12}

Measurements from URI12, a full-wave ambient noise tomographic model, are improved compared to models of CUB and TX11 (Figures 10 and 11). Phase delays from both ambient noise and earthquakes are well constrained without any apparent relationship with source-receiver distance. Nevertheless, as shown by the histogram of cross-correlation coefficients (Figure 12), the synthetic waveforms still cannot explain the observations adequately, especially at periods shorter than $35 \mathrm{~s}$ (beyond the frequency range used in the construction of the model). As shown in Figure 11, the phase delays are normally distributed, with an approximately zero mean from ambient noise and a negative average (within a range of $-0.6 \mathrm{~s}$ to $-3.7 \mathrm{~s}$ from longer to shorter periods; Table 3) from earthquakes. As the negative mean is independent of the interstation distance (Figure 10), it can at least partly be attributed to the contribution from uncertainties of earthquake source location and time. It is worth to point out that the construction of the URI12 model utilized the same forward wave simulation method as we use in this study. In addition, a small fraction ( $20 \%$ ) of the empirical Green's functions used in this validation were used in the construction of URI12, although no earthquake waveforms were used. Thus, we expect a more consistent (smaller) EGF phase delays for this model compared to other models. Nevertheless, the consistency of the ambient noise data with the regional earthquake data, which is independent of the Green's functions extracted from noise cross correlation, also suggests that the URI12 model can explain the observed waveforms in a better way.

\subsection{Models of DNA10 and Shen 13}

As these two models only cover the western and central U.S., the longest interstation distance is shorter compared to the above three models (Figure 10). For DNA10, phase delays at all the period bands increase positively with the increasing source-receiver distances (Figure 10), similar to the trend for TX11. This indicates that on average, DNA10 is too fast for the Earth structure in the western and central U.S. In contrast, the average phase delays from Shen13, a joint model of receiver function and surface wave tomography, are negative at all the three frequency bands (Figure 11), reflecting the lowest average velocities in the uppermost mantle and lower crust among the five models (Figure 3). Measurements from Shen 13 are less scattered compared to results from DNA10. Distribution of the cross-correlation coefficients by these two models shows similar patterns for ambient noise and earthquakes (Figure 12).

\section{Conclusions}

In this study, we simulate wave propagation within five 3-D shear wave velocity models of the United States and compare phase delays and correlation coefficients between observed and synthetic waveforms at multiple-period bands (within 15-75 s) to validate quantitatively and directly the models in the crust and uppermost mantle. Our results confirm the improvement of models in terms of model predictions with the increase of seismic data sets and implement of advanced seismological methods (URI12 and Shen 13 versus CUB, TX11, and DNA10). In general, earthquake phase delays are more scattered than those of ambient noise, likely reflecting uncertainties in earthquake location, origin time, and moment tensors. A positive linear trend between phase delay and interstation distance is observed for models of CUB, TX11, and DNA10 at periods of 25-75 s, indicating the faster-than-real structure. The similar trend of measurements for TX11 and DNA10 (Figure 10) is consistent with the similarity of their average velocity profiles (Figure 3). The two most recent models, Shen 13 and URI12, predict the phase arrivals more accurately than other models. For all of the five models, phase delays and cross-correlation coefficients within the crust (15-35 s periods) appear to be more scattered compared to results at longer periods, indicative of the unresolved complex crustal structure. The grid spacings used in our wave simulation are not fine enough to extend the comparison to shorter-period $(<15 \mathrm{~s})$ surface waves, which are affected by the complexity of the shallow crustal structure (see supporting information).

We note that the $P$ wave velocity in the shallowest crust affects Rayleigh waves $(<10 \mathrm{~km}$ for up to $50 \mathrm{~s}$ period Rayleigh waves). For scale, a $\pm 10 \% P$ wave velocity variation in the upper $\sim 15 \mathrm{~km}$ crust can result in up to $\pm 1.5 \mathrm{~s}$ phase arrival time change for a Rayleigh wave with a period of $25-50 \mathrm{~s}$ and traveling between two 
stations separated by $\sim 580 \mathrm{~km}$. So uncertainties in the conversion from $V_{s}$ to $V_{p}$ in the construction of the models for simulation may result in minor errors compared to the discrepancies between the observed and synthetics (Figure 10).

As discussed in section 2, the criteria for model selection in this study limit the type and number of velocity models to be tested. Present body wave tomographic models in the United States are consistent in pattern at large scales [e.g., Becker, 2012] and provide velocity perturbations to the mantle transition zone. Many of the body wave tomographic models cannot be tested and validated in this study because of the difficulty to accurately convert the velocity perturbation to absolute shear wave velocity. Moreover, the lack of the attenuation structure in the models also prevents us from validating the deeper mantle structure of the models. The coherency of phase velocities and attenuation coefficients in the western U.S. [Lawrence and Prieto, 2011] suggests the necessity of a combined velocity and attenuation structure from the crust to the mantle. Sensitivities of various seismic waves to the Earth structure vary from the surface to the mantle; thus, to obtain a comprehensive Earth model, we need to combine all the usable seismic data sets, include anisotropy and attenuation, and improve the solution of earthquake source location and moment tensors. Finally, we strongly emphasize that this study validates only parts of the selected model, particularly for the ones constrained or partially constrained by body waves (TX11 and DNA10), which extend to deep mantle. So the comparison should not be used in any way to rank the models. The results should be interpreted only as an assessment of the state of our ability to predict a limited set of seismic observations and the collective need for further model improvement.

\section{Acknowledgments}

All the seismic data are requested from the IRIS Data Management Center. The earthquake source information are downloaded from the global CMT solutions (http://www.globalcmt.org). We thank all the authors who generously allow us to use their models or make the model accessible through the Web link. The empirical Green's functions extracted from ambient noise, the synthetic seismic waveforms generated in this study, and the phase delays from ambient noise and regional earthquakes are available upon a request to the authors. Comments from Editor Robert Nowack, an Associate Editor Fan-Chi Lin, and one anonymous reviewer significantly help improve the manuscript. This research is supported by the National Science Foundation (grant 1144771) and the Air Force Research Laboratory (award FA9453-13-C-0362).

\section{References}

Abers, G. A., L. S. MacKenzie, S. Rondenay, Z. Zhang, A. G. Wech, and K. C. Creager (2009), Imaging the source region of Cascadia tremor and intermediate-depth earthquakes, Geology, 37, 1119-1122, doi:10.1130/G30143A.1.

Audet, P., M. G. Bostock, N. I. Christensen, and S. M. Peacock (2009), Seismic evidence for overpressured subducted oceanic crust and mega-thrust fault sealing, Nature, 457, 76-78.

Becker, T. W. (2012), On recent seismic tomography for the western United States, Geochem. Geophys. Geosyst., 13, Q01W10, doi:10.1029/ $2011 \mathrm{GC} 003977$.

Bedle, H., and S. van der Lee (2009), S velocity variations beneath North America, J. Geophys. Res., 114, B07308, doi:10.1029/2008JB005949.

Behn, M. D., G. Hirth, and J. R. Elsenbeck II (2009), Implications of grain size evolution on the seismic structure of the oceanic upper mantle, Earth Planet. Sci. Lett., 282, 178-189.

Bozdag, E., and J. Trampert (2010), Assessment of tomographic mantle models using spectral element seismograms, Geophys. J. Int., 180, $1187-1199$. Brocher, T. M. (2005), Empirical relations between elastic wave speeds and density in the Earth's crust, Bull. Seismol. Soc. Am., 95(6), 2081-2092.

Burdick, S., C. Li, V. Martynov, T. Cox, J. Eakins, T. Mulder, L. Astiz, F. L. Vernon, G. L. Pavlis, and R. D. van der Hilst (2008), Upper mantle heterogeneity beneath North America from travel time tomography with global and USArray Transportable Array data, Seismol. Res. Lett., 79, 384-392.

Burdick, S., R. D. van der Hilst, F. L. Vernon, V. Martynov, T. Cox, J. Eakins, L. Astiz, and G. L. Pavlis (2010), Model Update January 2010: Upper mantle heterogeneity beneath North America from travel time tomography with global and USArray Transportable Array data, Seismol. Res. Lett., 81, 689-693.

Calkins, J. A., G. A. Abers, G. Ekström, K. C. Creager, and S. Rondenay (2011), Shallow structure of the Cascadia subduction zone beneath western Washington from spectral ambient noise correlation, J. Geophys. Res., 116, B07302, doi:10.1029/2010JB007657.

Cammarano, F., S. Goes, P. Vacher, and D. Giardini (2003), Inferring upper-mantle temperatures from seismic velocities, Phys. Earth Planet. Inter., 138, 197-222.

Christensen, N. I., and W. D. Mooney (1995), Seismic velocity structure and composition of the continental crust: A global view, J. Geophys. Res., 100, 9761-9788, doi:10.1029/95JB00259.

Dalton, C. A., G. Ekström, and A. M. Dziewonski (2008), The global attenuation structure of the upper mantle, J. Geophys. Res., 113, doi:10.1029/2007JB005429.

Delorey, A. A., and J. E. Vidale (2011), Basin shear-wave velocities beneath Seattle, Washington, from noise-correlation Rayleigh waves, Bull. Seismol. Soc. Am., 101, 2162-2175, doi:10.1785/0120100260.

Dziewonski, A. M., T.-A. Chou, and J. H. Woodhouse (1981), Determination of earthquake source parameters from waveform data for studies of global and regional seismicity, J. Geophys. Res., 86, 2825-2852, doi:10.1029/JB086iB04p02825.

Ekström, G., M. Nettles, and A. M. Dziewonski (2012), The global CMT project 2004-2010: Centroid-moment tensors for 13,017 earthquakes, Phys. Earth Planet. Inter., 200-201, 1-9, doi:10.1016/j.pepi.2012.04.002.

Faul, U. H., and I. Jackson (2005), The seismological signature of temperature and grain size variations in the upper mantle, Earth Planet. Sci. Lett., 234, 119-134.

Gao, H., and Y. Shen (2012), Validation of shear-wave velocity models of the Pacific Northwest, Bull. Seismol. Soc. Am., $102(6), 2611-2621$.

Gao, H., and Y. Shen (2014), Upper mantle structure of the Cascades from full-wave ambient noise tomography: Evidence for 3-D mantle upwelling in the back-arc, Earth Planet. Sci. Lett., 309, 222-233, doi:10.1016/j.epsl.2014.01.012.

Gao, H., E. D. Humphreys, H. Yao, and R. D. van der Hilst (2011), Crust and lithosphere structure of the northwestern U.S. with ambient noise tomography: Terrane accretion and Cascade arc development, Earth Planet. Sci. Lett., 304, doi:10.1016/j.epsl.2011.01.033.

Godey, S., F. Deschamps, J. Trampert, and R. Snieder (2004), Thermal and compositional anomalies beneath the North American continent, J. Geophys. Res., 109, B01308, doi:10.1029/2002JB002263.

Goes, S., R. Govers, and P. Vacher (2000), Shallow mantle temperatures under Europe from P and S wave tomography, J. Geophys. Res., 105(B5), 11,153-11,169, doi:10.1029/1999JB900300. 
Grand, S. P. (2002), Mantle shear-wave tomography and the fate of subducted slabs, Philos. Trans. R. Soc. London, 360, $2475-2491$.

Hammond, W., and E. D. Humphreys (2000), Upper mantle seismic wave velocity: Effect of realistic partial melt geometries, J. Geophys. Res. 105, 10,975-10,986, doi:10.1029/2000JB900041.

James, D. E., M. J. Fouch, R. W. Carlson, and J. B. Roth (2011), Slab fragmentation, edge flow and the origin of the Yellowstone hotspot track, Earth Planet. Sci. Lett., doi:10.1016/j.epsl.2011.09.007.

Kennett, B. L. N., E. R. Engdahl, and R. Buland (1995), Constraints on seismic velocities in the Earth from travel times, Geophys. J. Int., 122, 108-124.

Lawrence, J. F., and G. A. Prieto (2011), Attenuation tomography of the western United States from ambient seismic noise, J. Geophys. Res., 116, B06302, doi:10.1029/2010JB007836.

Moschetti, M. P., M. H. Ritzwoller, F.-C. Lin, and Y. Yang (2010), Crustal shear wave velocity structure of the western United States inferred from ambient seismic noise and earthquake data, J. Geophys. Res., B10306, doi:10.1029/2010JB007448.

Obrebski, M., R. M. Allen, M. Xue, and S.-H. Hung (2010), Slab-plume interaction beneath the Pacific Northwest, Geophys. Res. Lett., 37, L14305, doi:10.1029/2010GL043489.

Obrebski, M., R. M. Allen, F. Pollitz, and S.-H. Hung (2011), Lithosphere-asthenosphere interaction beneath the western United States from the joint inversion of body-wave travel times and surface-wave phase velocities, Geophys. J. Int., 185, 1003-1021.

Pavlis, G. L., K. Sigloch, S. Burdick, M. Fouch, and F. L. Vernon (2012), Unraveling the geometry of the Farallon plate: Synthesis of three-dimensional imaging results from USArray, Tectonophysics, doi:10.1016/j.tecto.2012.02.008.

Porritt, R. W., R. M. Allen, D. C. Boyarko, and M. R. Brudzinski (2011), Investigation of Cascadia segmentation with ambient noise tomography, Earth Planet. Sci. Lett., 309, 67-76, doi:10.1016/j.epsl.2011.06.026.

Porritt, R. W., R. M. Allen, and F. F. Pollitz (2013), Seismic imaging east of the Rocky mountains with USArray, Earth Planet. Sci. Lett., doi:10.1016/j.epsl.2013.10.034.

Qin, Y., Y. Capdeville, J.-P. Montagner, L. Boschi, and T. W. Becker (2009), Reliability of mantle tomography models assessed by spectral-element simulation, Geophys. J. Int., 177, 125-144.

Roth, J. B., M. J. Fouch, D. E. James, and R. W. Carlson (2008), Three-dimensional seismic velocity structure of the northwestern United States, Geophys. Res. Lett., 35, L15304, doi:10.1029/2008GL034669.

Sabra, K. G., P. Roux, and W. A. Kuperman (2005), Emergence rate of the time-domain Green's function from the ambient noise cross-correlation function, J. Acoust. Soc. Am., 118, 3524-3531.

Savage, B., D. Komatitsch, and J. Tromp (2010), Effects of 3-D attenuation on seismic wave amplitude and phase measurements, Bull. Seismol. Soc. Am., 100(3), 1241-1251, doi:10.1785/0120090263.

Schmandt, B., and E. Humphreys (2010), Complex subduction and small-scale convection revealed by body-wave tomography of the western United States upper mantle, Earth Planet. Sci. Lett., 297, 435-445.

Schmandt, B., and E. Humphreys (2011), Seismically imaged relict slab from the 55 Ma Siletzia accretion to the northwest United States, Geology, 39, 175-178.

Shapiro, N. M., and M. H. Ritzwoller (2002), Monte Carlo inversion for a global shear velocity model of the crust and upper mantle, Geophys. J. Int., 151, 88-105.

Shen, Y. (2012), Seismic evidence for deep tectonic control on the transition from magma-rich to magma-poor continental breakup at the Eastern North American Margin, abstract T51A-2560, AGU Fall Meeting, San Francisco, Calif., Dec. 3-7. [Available at https://www. researchgate.net/publication/266332582_Seismic_Evidence_for_Deep_Tectonic_Control_on_the_Transition_from_MagmaRich_to_Magma-Poor_Continental_Breakup_at_the_Eastern_North_American_Margin.]

Shen, W., M. H. Ritzwoller, and V. Schulte-Pelkum (2013), A 3-D model of the crust and uppermost mantle beneath the Central and western U.S by joint inversion of receiver functions and surface wave dispersion, J. Geophys. Res. Solid Earth, 118, 262-276, doi:10.1029/2012JB009602.

Shen, Y., Y. Ren, H. Gao, and B. Savage (2012), An improved method to extract very broadband empirical green's functions from ambient seismic noise, Bull. Seismol. Soc. Am., 102(4), 1872-1877, doi:10.1785/0120120023.

Sigloch, K. (2011), Mantle provinces under North America from multi-frequency P wave tomography, Geochem. Geophys. Geosyst., 12, Q02W08, doi:10.1029/2010GC003421.

Simmons, N. A., S. C. Myers, G. Johannesson, and E. Matzel (2012), LLNL-G3Dv3: Global $P$ wave tomography model for improved regional and teleseismic travel time prediction, J. Geophys. Res., 117, B10302, doi:10.1029/2012JB009525.

Snieder, R. (2004), Extracting the Green's function from the correlation of coda waves: A derivation based on stationary phase, Phys. Rev. E., 69, 046610, doi:10.1103/PhysRevE.69.046610.

Snieder, R. (2007), Extracting the Green's function of attenuating heterogeneous acoustic media from uncorrelated waves, J. Acoust. Soc. Am., 121(5), 2637-2643.

Song, T.-R. A., and D. V. Helmberger (2007), Validating tomographic model with broad-band waveform modeling: An example from the LA RISTRA transect in the southwestern United States, Geophys. J. Int., 171, 244-258.

Stehly, L., M. Campillo, and N. M. Shapiro (2007), Traveltime measurements from noise correlation: Stability and detection of instrumental time-shifts, Geophys. J. Int., 171, 223-230, doi:10.1111/j.1365-246X.2007.03492.x.

Takei, Y. (2002), Effect of pore geometry on $V_{p} / V_{s}$ : From equilibrium geometry to crack, J. Geophys. Res., 107, doi:10.1029/2001JB000522.

Tian, Y., Y. Zhou, K. Sigloch, G. Nolet, and G. Laske (2011), Structure of North American mantle constrained by simultaneous inversion of multiple-frequency SH, SS, and Love waves, J. Geophys. Res., 116, B02307, doi:10.1029/2010JB007704.

Tsai, V. C., and M. P. Moschetti (2010), An explicit relationship between time-domain noise correlation and spatial autocorrelation (SPAC) results, Geophys. J. Int., 182(1), 454-460, doi:10.1111/j.1365-246X.2010.04633.x.

Wagner, L. S., M. J. Fouch, D. James, and S. Hanson-Hedgecock (2012), Crust and upper mantle structure beneath the Pacific Northwest from joint inversions of ambient noise and earthquake data, Geochem., Geophys., Geosyst., 13, Q0AN03, doi:10.1029/2012GC04353.

Wapenaar, K. (2004), Retrieving the elastodynamic Green's function of an arbitrary inhomogeneous medium by cross correlation, Phys. Rev. Lett., 93, 254301, doi:10.1103/PhysRevLett.93.254301.

Wapenaar, K., and J. Fokkema (2006), Green's function representations for seismic interferometry, Geophysics, 71, S133-S146.

Yang, Y., and M. H. Ritzwoller (2008), Characteristics of ambient seismic noise as a source for surface wave tomography, Geochem., Geophys., Geosyst., 9, Q02008, doi:10.1029/2007GC001814.

Yang, Y., M. H. Ritzwoller, F.-C. Lin, M. P. Moschetti, and N. M. Shapiro (2008), Structure of the crust and uppermost mantle beneath the western United States revealed by ambient noise and earthquake tomography, J. Geophys. Res., 113, B12310, doi:10.1029/2008JB005833.

Yuan, H., B. Romanowicz, K. M. Fischer, and D. Abt (2011), 3-D shear wave radially and azimuthally anisotropic velocity model of the North American upper mantle, Geophys. J. Int., 184, 1237-1260.

Zhang, W., Y. Shen, and L. Zhao (2012), Three-dimensional anisotropic seismic wave modeling in spherical coordinate by a collocated-grid finite difference method, Geophys. J. Inter., 188, 1359-1381, doi:10.1111/j.1365-246X.2011.05331.x. 